\title{
Anion Concentration Distribution and Tourism Resources Analysis of Guizhou Province
}

\author{
Yueai $\mathrm{CHEN}^{1}$, Qingshan LI ${ }^{1}$, Yanmin QIAN ${ }^{1}$, \\ Jinqiong $\mathrm{LUO}^{1}$ \\ ${ }^{1}$ Old expert technology center \\ Chinese academy of sciences \\ Beijing, China \\ e-mail:573562982@qq.com, qsli@ysu.edu.cn
}

\begin{abstract}
This paper introduced the overall situation and tourism resources in Guizhou Province, and studied the anion distribution and air quality of scenic places of this region based on the results obtained by the test of some scenic spot, Using city gravity model and actual data, analysis the potential visitors in the surrounding provinces and cities in Guizhou Province even nationwide, according to the actual situation of the region, with the main idea of "Strive for tourists in the surrounding provinces and cities and attract tourists in more distant regions", we put forward some feasible suggestions, at the same time, uses the concept of "bring home the anion environment, building the permanent Great Wall of health", provides some idea for the facilities construction of scenic areas.
\end{abstract}

Keywords-Guizhou province; air anion; gravitational models; tourism attraction

\section{INTRODUCTION}

Guizhou, also called 'Qian' or 'Gui', is located in the southeast, southwest China. The provincial capital-Guiyang, is inland and mountainous province. Guizhou, which is $595 \mathrm{~km}$ long from west to east and $509 \mathrm{~km}$ width from south to north, is in the centre of five provinces, with Hunan in the east, Guangxi in the south, Yunnan in the west, and Sichuan and Chongqing in the north. The land area is about 176167 square kilometers, accounting for $1.8 \%$ of the nation's total, accompanied by $30.8 \%$ forest coverage rate and 35.02 million inhabitants. There are nine areas under administration, including Guiyang city, Liupanshui city, Zhunyi city, Anshun city, Tongren city, Bijie city, the Yi and Miao nationality autonomous prefecture in the west, the Miao nationality and Dong minority autonomous prefecture in the southeast, the Yi and Miao nationality autonomous prefecture in the south, reaching 49 national components in total. Belonging to a humid subtropical monsoon climate, the provincial landscape can be summarized into plateaus, mountains, hills and basins, and it is the only province without plain supports nationwide. Karst landform is typical there, exposed area of which reach 109084 square kilometers, accounting for $61.9 \%$ of the province's land area. It's wide distribution, complete type, and obvious regional differentiation that constitutes a special kind of karst

\author{
Dawei $\mathrm{WU}^{2}$ \\ ${ }^{2}$ State Key Laboratory for Metalstable Materials and \\ Technology \\ Yanshan University \\ Qinhuangdao, China \\ e-mail: 1220524190@qq.com
}

ecosystem. Guizhou is also rich in natural resources, especially energy, mineral, biology, and unique tourism resources.

There are magic beautiful natural scenery, colorful water-eroded cave landscape, wildlife wonders, cultural and the revolutionary relics in Guizhou, and mountain, forest, stone, water and hole are all included. There are 1 world natural heritage 'South China karst' and 4 national 5 A-class tourist area, such as 'Huangguoshu waterfalls', 58 national 4 A-class tourist area, such as 'Fanjing mountain', 18 statelevel scenic spots, such as 'Huangguoshu', 9 state-level national reserve, 22 national forest park, such as 'Azalea sea', 7 national geological park, such as 'Zhijin hole', 4 international ethnic ecological museum, such as 'Liuzhisuojia', 39 national key cultural relics protection units such as 'Qinglong hole', 31 state-level non-material cultural heritage such as 'Dong minority song', 18000 the ethnic cultural tourism village. It's multi-ethnic, long and splendid history and culture, rich and mysterious folk customs, mild and pleasant climate that makes Guizhou the ideal resorts for tourist and health.

\section{The Test of Air ANion CONCENTRAtion}

At present, a rising number of people pay attention to the regimen and health care. For anion has good health care function [1 4], it has become one of the important factors to attract tourists. Therefore, anion concentration in Guizhou has been tested.

Using DLY-6A-232 type air anion concentration testing instrument to test air anion [5],we obtained four data from different directions, south, east, north, west in detail, at each observation point. It takes 140 s to obtain a data, after getting overall four data at each observation point, we can regard the average one as the results. In this paper, we evaluate the level of air quality standard and the air fresh degree according to the seven levels standard evaluation system of air anion and the anion concentration relationship with human health[6], which proposed by Professor Qingshan Li of Yanshan University.

\section{A. $\quad$ Testing Results}

The results are shown in Tab.1 and Fig.1. 
TABLE I. ANION CONCENTRATION STATISTICS OF PARTIAL SCENIC SPOTS IN GUIZHOU

\begin{tabular}{|c|c|c|c|c|c|}
\hline Scenic spots & $\begin{array}{c}\text { Average } \\
(\text { anion/cm }\end{array}$ & $\begin{array}{c}\text { Maximum } \\
\left(\text { anion/ } \mathrm{cm}^{3}\right)\end{array}$ & $\begin{array}{c}\text { Minimum } \\
(\text { anion/cm }\end{array}$ & Grade & $\begin{array}{c}\text { Degree of fresh } \\
\text { air }\end{array}$ \\
\hline Huangguoshu waterfall & 24691 & 26030 & 23750 & Super & Super fresh \\
\hline One corner of Longgong & 1698 & 2880 & 980 & 2 & Fresh \\
\hline Azalea sea & 2136 & 3080 & 1120 & 1 & Very fresh \\
\hline Qiebozhangjiang & 2072 & 3430 & 1060 & 1 & Very fresh \\
\hline Shuichun river & 2030 & 3170 & 1380 & 1 & Very fresh \\
\hline Wuyang riber & 1984 & 4100 & 780 & 2 & Fresh \\
\hline Fanjing mountain & 1680 & 2380 & 890 & 2 & Fresh \\
\hline Wanfeng forest & 2967 & 5270 & 1310 & 1 & Very fresh \\
\hline Pingtang national geological park & 1733 & 2920 & 830 & 2 & Fresh \\
\hline Qianlingshan park & 1580 & 2450 & 1190 & 2 & Fresh \\
\hline Xijiang qianhu Hmong village & 1620 & 2420 & 1050 & 2 & Fresh \\
\hline Zhenyuan ancient town & 1451 & 2150 & 1160 & 3 & Light fresh \\
\hline Zhaoxing Dong minority village & 1688 & 2280 & 970 & 2 & Fresh \\
\hline
\end{tabular}

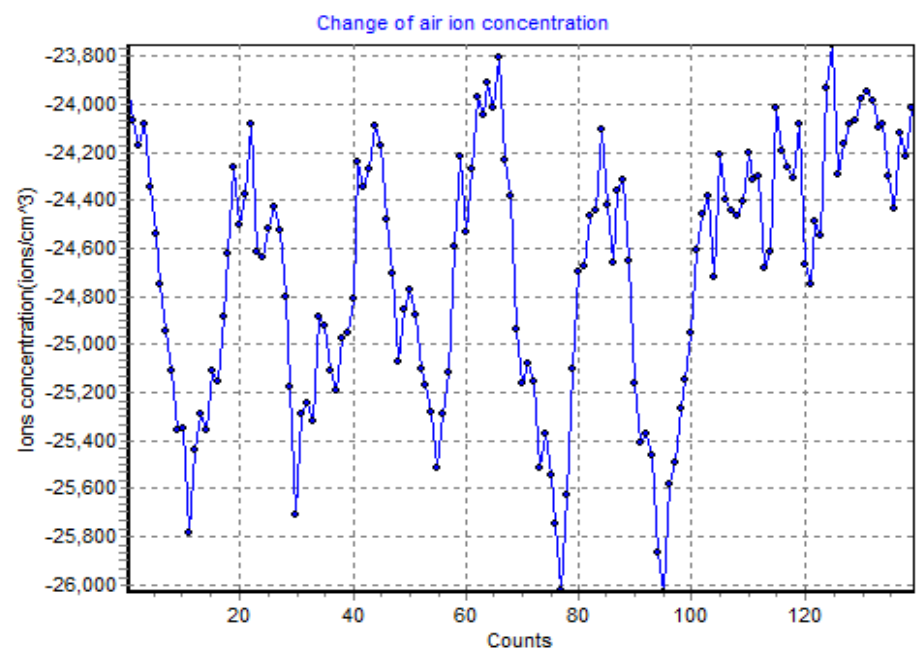

Figure 1. Anion concentration data graph around Huangguoshu waterfall.

\section{B. Analysis}

Anion concentration detection results show that air quality of part of the scenic area being tested in Guizhou is very good, and it is very beneficial to human body health for the average concentration of anions can reach secondary and above level, even the super level. Combined with the existing research, we can conclude that Guizhou is very livable, also a wonderful place to relax and recuperate, of high value in health and tourism.

\section{POTENTIAL CONTRIBUTION GRAVITY MODEL ANALYSIS IN GUIZHOU TOURISM MARKET}

\section{A. Introduction of Tourism Gravity Model Analysis}

Tourism gravity model $[1,7]$ is from trade gravity model, using one factor or space distance between two regions to analyze one region's attraction to tourists. The basic idea is that gravity in tourist area to the surrounding area is positively correlated with population, GDP per capita, GDP 
in the target areas and negatively correlated with the distance between the two regions.

Attraction index Fi is shown by the following formula:

$\mathrm{Fi}=\mathrm{MiMj} / \mathrm{d} 2 \mathrm{ij}$
Among them, Mi, Mj represents characteristic value of the two regions, such as population, GDP, GDP per capita dij represtents the distance between the two regions.

The market potential for regional market share:

$$
\mathrm{Wi}=\mathrm{Fi} / \sum \mathrm{Fi}
$$

TABLE II. RANKING TABLE OF CHINESE LATEST CITIES POPULATION IN 2013-2014

\begin{tabular}{|c|c|c|c|c|}
\hline Cities & $\begin{array}{c}\text { Population } \\
\left(* 10^{4}\right)\end{array}$ & $\begin{array}{c}\text { GDP } \\
\left(* 10^{8} \mathrm{RMB}\right)\end{array}$ & $\begin{array}{c}\text { GDP per capita } \\
(\mathrm{RMB} / \mathrm{per} \text { capita })\end{array}$ & $\begin{array}{c}\text { Distance } \\
(\mathrm{KM})\end{array}$ \\
\hline Guiyang & 432.46 & 1,122 & 25,941 & - \\
\hline Chengdu & 1404.76 & 5,551 & 39,518 & 519 \\
\hline Chongqing & 2884.62 & 7,894 & 27,367 & 647 \\
\hline Changsha & 704.41 & 4,547 & 64,551 & 452 \\
\hline Nanning & 666.16 & 1,800 & 27,027 & 423 \\
\hline Kunming & 643.20 & 2,120 & 32,966 & 638 \\
\hline Guangzhou & 1270.08 & 10,604 & 83,495 & 1527 \\
\hline Shanghai & 2301.91 & 16,872 & 73,297 & 1132 \\
\hline Zhengzhou & 862.65 & 4,000 & 46,369 & 1734.5 \\
\hline Beijing & 1961.24 & 13,778 & 70,251 & 647 \\
\hline
\end{tabular}

TABLE III. MARKET SHARE UNDER DIFFERENT INDEXES OF VARIOUS PROVINCIAL CAPITAL

\begin{tabular}{|c|c|c|c|c|c|c|c|}
\hline \multirow[b]{3}{*}{ Cities } & \multicolumn{6}{|c|}{ Indexes } & \multirow{3}{*}{$\begin{array}{c}\text { Incorporative } \\
\text { Market share } \\
\text { (\%) }\end{array}$} \\
\hline & \multicolumn{2}{|c|}{ Population } & \multicolumn{2}{|c|}{ GDP } & \multicolumn{2}{|c|}{ GDP per capita } & \\
\hline & $\begin{array}{c}\text { Gravitation } \\
\text { F }\end{array}$ & $\begin{array}{c}\text { Market } \\
\text { share } \\
\mathrm{W}_{1}(\%)\end{array}$ & $\begin{array}{c}\text { Gravitation } \\
\text { F }\end{array}$ & $\begin{array}{c}\text { Market } \\
\text { share } \\
\mathrm{W}_{2}(\%)\end{array}$ & $\begin{array}{c}\text { Gravitation } \\
\text { F }\end{array}$ & $\begin{array}{c}\text { Market } \\
\text { share } \\
\mathrm{W}_{3}(\%)\end{array}$ & \\
\hline Chengdu & 2.26 & 13.48 & 23.12 & 14.05 & 3805.81 & 13.35 & 13.63 \\
\hline Chongqing & 8.46 & 50.48 & 60.07 & 36.51 & 4814.50 & 16.89 & 34.63 \\
\hline Changsha & 0.73 & 4.36 & 12.19 & 7.41 & 4000.19 & 14.03 & 8.60 \\
\hline Nanning & 1.41 & 8.41 & 9.89 & 6.01 & 3431.69 & 12.04 & 8.82 \\
\hline Kunming & 1.55 & 9.25 & 13.29 & 8.08 & 4779.39 & 16.76 & 11.36 \\
\hline Guangzhou & 1.35 & 8.05 & 29.23 & 17.76 & 5321.15 & 18.66 & 14.82 \\
\hline Shanghai & 0.43 & 2.57 & 8.12 & 4.93 & 815.45 & 2.86 & 3.45 \\
\hline Zhengzhou & 0.29 & 1.73 & 3.50 & 2.13 & 938.69 & 3.29 & 2.38 \\
\hline Beijing & 0.28 & 1.67 & 5.14 & 3.12 & 605.75 & 2.12 & 2.30 \\
\hline
\end{tabular}




\section{B. Regional Market share of the Surrounding Provinces}

Based on the surrounding provinces and municipality, this part analyzed potential tourism market of Guizhou by simulating tourism gravity to different provincial capital. Three characteristic values---the population, the city of wealth and income per capita---are applied to calculate the index of gravity.

Sichuan, Chongqing, Hunan, Guangxi, Yunan provinces are adjacent to Guiyang. Concentrating on Chengdu, Chongqing, Changsha, Nanning, Kunming, Guangzhou, Shanghai, Zhengzhou, Beijing, we obtained the urban population, GDP, GDP per capita, and the distance between the target city to Guiyang, which is shown on table 2, referring to Chinese latest cities population and the distance between the provincial capital cities in China in 2013-2014. Then, these data were applied to attraction index formula to acquire regional market share for each provincial city, which are shown on table 3.

As table 3 shown, Chongqing, Chengdu, Kunming and Guangzhou occupy a relatively large market share, and Shanghai, Beijing and Zhengzhou has smaller market share, while the market shares of nanning and changsha is intermediate. Combined with the results from table 2, we can achieve that the closer the distance between the target province to Guizhou, the greater its contribution to the tourism industry in Guizhou. Although Beijing and Shanghai has superiority in population, GDP and per capita GDP, it's distance that restricts local tourists travelling to Guizhou.

\section{CONCLUSION}

\section{A. Suggestions to Tourism Development in Guizhou}

Obviously can we get that the surrounding provinces are the biggest customer group comparing gravity model analysis and physical truth. And for other provinces, their market share is relatively small individually. However, as many a mickle makes a muckle, the aggregated influence from all of them on tourism in Guizhou is also considerable. We put forward some feasible suggestions under the main idea of "Strive for tourists in the surrounding provinces and cities and attract tourists in more distant regions".

Traffic is priority in order to attract those potential tourists in the surrounding provinces or other. The additional construction of non-stop train or high speed train from scenic region to various provinces is necessary to make trip convenient, avoiding the waste of time on the road. Another factor which influences tourism so much is price. As we all know small profits but quick turnover, lower scenic spot ticket can arouse more tourists going outside the home. The third suggestion is to improve popularity and influence of tourism in Guizhou, build ecological tourism model and shape unique tourism image by taking full advantage of media, network and communication. For example, scenic spot can invite reality TV show with high ratings to filming. The following advice is to strengthen characteristic and tourism linkage between the scenic spots, and improve the quality of tourism, implement one package service of each scenic spot. The fifth suggestion is to perfect tourism facilities. Finally, meet the needs of tourists from all aspects by establishing food festival and cultural festival, setting up service places like shopping, post and telecommunication, medical assistance, strengthening the service level.

In addition, according to the anion distribution test and research of the characteristic of forest anion distribution [811], anionic materials can be used to construct scenic spots under theoretical guidance of ecological environment model of Guizhou and concept of "bring home the anionic environment, building the permanent Great Wall of health". For instance, anion asphalt [12] can be used to pave road in scenic spot, and anion coating can be used to painting the walls and floors, etc. Meanwhile, fountain, waterfall can be built in the scenic region with fewer anion concentrations, which can improve air quality to obtain the effect of relaxing and health protection.

\section{ACKNOWLEDGMENT}

The organizing committee of large-scale culture project of public welfare of bring honor to China Activity.

\section{REFERENCES}

[1] Cai B, Li Q, Zhang S, et al. Anion Concentration Distribution and Tourism Resources Gravity Analysis in Shijiazhuang[J]. Advances in Environmental Protection, 2013, 3(2).

[2] Shang Huili, Li Qingshan, Liu Ziyu. Yanshan University of negative air ions concentration distribution and learning environment analysis $[\mathrm{J}]$. Collected papers of the 7 th world academic conference on natural medicine,2013.

[3] M. Zhang, P. Yu. The study of evaluation standards and the distribution concentration of air anion in Dalian. China Advanced Materials Research, 2010, (96): 271 276.

[4] Siren Lan. Theory and practice of national forest park[M]. Beijing: Chinese forestry press, 2004: 336 340

[5] The state administration of quality supervision, inspection and quarantine of the People's Republic of China. General specification of anion measuring instrument[S]. The national standard of the People's Republic of China,2002.

[6] Qingshan Li, Jun Li, Youbo Di, etc. Anion concentration determination of Beidaihe and anion evaluation standards[J]. Academic journal of Chinese environmental management cadre institute, 2008, 18(4):1-3.

[7] Aijun Liao. Tourist attraction and gravity model research[D]. Beijing Forestry University, 2005.

[8] Xiao Liu, Jihui Sun, Fangjun Ding, etc. Air purification function evaluation of forest ecosystem in Guizhou[J]. Forestry survey planning, 2013, 38(4): 50-54.

[9] Hui Li. A preliminary study on anion resources of part of the forest park in Guizhou[D]. Guizhou University, 2008.

[10] Xiangjiang Meng, Yuanzhao Hou, Yuming Li, etc. Anion distribution characteristic and quality evaluation of Qiannan prefecture forest in Guizhou [J]. Journal of Guizhou agricultural science, 2012, 40(8): 179-182.

[11] Jianchun Yang. An empirical analysis of the relationship between economic growth and tourism in Guizhou[J]. Social science in q, 2010 (5): 80-84.

[12] Wei Hong, Qingshan Li, Guoquan Guan, etc. The performance and application of a kind of anion rubber modified asphalt used in the road [J]. Chinese science bulletin, 2013, 58(1):92 97. 